\title{
1. The methodology of comparative history of political thought
}

Comparative political thought can benefit from a more methodologically informed approach. There is a growing literature on comparative political thought including its methodology, but discussion of method is still in its infancy. This chapter outlines the methodological approach that underpins this history. It is not comprehensive nor is it applied consistently but it is an attempt to lay out the type of issues raised by this type of study in a fairly thoughtful and systematic way.

First, I set out certain basic methodological principles used in this work. I note that it is usually better to compare two thinkers and though not necessarily from the same time period, in the case of this book, I have been compelled to focus on many thinkers who are roughly contemporaries based on loose periodization. The next task in comparison is to consider what it is that is comparable so a comparison can be made. This also raises issues about language, which is not uncommon in the study of the history of political thought, but this book takes language much more seriously across a number of languages. Next, I highlight the importance of metaphysics, that is, the assumptions about the way the universe works that underlie the ethical and political relationships posited by key thinkers. Metaphysics is often ignored or explained away by studies of political thinkers but it is central to understanding political thought, even in contemporary thinkers. This sets the background to this work.

The main contributions to the methodology of the comparative political thought in the rest of this chapter are fourfold. The first is to insist that once any similarities have been explored, it is essential then to point out the inevitable differences that remain because it is a mistake to leave any comparison to rest on what might be superficial similarities. The second is the attempt to steer a middle course between historicism and universalism by using the notion of a productive unresolved dialectic between historical context and universal concepts. The third is the development of the principle of charity that raises it from a mere rhetorical device to methodological tool. The final contribution is to establish criteria for validity in the assessment of texts.

At the end of the chapter, I provide a brief outline of the type of questions pursued and why it is necessary to look at certain subjects more or 
less consistently across the chapters in order to produce a work that is a true world history of political thought.

\section{BASIC METHODOLOGICAL PRINCIPLES}

The first methodological consideration is scope. Primarily, the focus should be on individual thinkers because it provides the most concrete basis for comparison. It is true that in many cases one must compare two or more schools of thought rather than individual thinkers within these schools. Yet, the notion of schools of thought is problematic. It is only used when there is no alternative given the need to avoid too much complexity and try to produce a concise and readable account. Largely, however, the focus is on individual thinkers.

The number of cases to be compared also requires consideration. It is best to compare only two thinkers at a time, which provides for more clarity, coherence and depth. Where it is necessary to expand the number of comparators to be more fully comprehensive, the discussion is more complex and care must be taken to make sure that clarity and coherence is not lost as a result.

If a comparison is to be made, then another key consideration is a justification of the comparison. It is easier, of course, if others have said that they are similar because then one can simply cite the relevant studies and arguments. Where there is no obvious basis for comparison in the literature then some rationale must be made for comparison of thinkers, even if it is just to contrast the two.

In each case, there is a need to select topics for comparison. Within the range of topics raised by each thinker, there will always be a few key areas that are most relevant. First of all, the focus needs to be on the ones for which the thinker is most famous as noted by others in the academic literature and more broadly if necessary. Therefore, it is necessary to summarize the overall arguments of each thinker at the start of the discussion. In many cases, the overview will seem too brief but the value of comparison is not in the depth devoted to any individual thinker's ideas alone but in comparison with others.

Where possible I have compared thinkers and systematically on the same ideas or topics whether or not these ideas are shared. For example, if one thinker is deeply religious and another is not, I tried to be sure to explore the role of religion in both because it may be that religion plays an important role in general so ignoring it in one might overemphasize it in the other. In short, it is best to compare thinkers on the same topics consistently. Nonetheless, I have tried to highlight areas which are not 
the most obvious and attractive aspects of the thinkers and do not ignore inconvenient ideas which do not fit easily into the narrative structures. One must confront difficult ideas or problems for any generalizations by looking at exceptions and inconsistencies.

Related to the basis of justification for the thinkers and topics compared in this book is the problem of sequence. The comparisons are between roughly contemporaneous thinkers because of the chronological nature of the narrative in this book. This is not strictly necessary and there are points at which parallels or contrasts with thinkers from disparate historical periods are appropriate. Fitting all contemporary thinkers into a narrative has been difficult to sustain at points, but it was necessary to provide some form of sequential historical periodization, however forced in some cases. Not all historical periods can be said to naturally produce similar political thought, especially in the early periods where there is little or no contact between the major civilizations. The periodization is somewhat contrived and not always satisfactory. At the same time, it often appears that similar ideas and thinkers appear in historical conditions that do bear a good deal of resemblance. At least there is enough similarity to provide a useful narrative to hold the discussion together.

One task of the comparisons is to explore whether or not there is a basis to these shared characteristics. The overarching themes of the sections and implicit in the chapters, such as "first major thinkers," "first empires," "medieval," "renaissance," "reform" are originally derived from Western historical periodization and admittedly biased to a degree as a result. A better division of historical time frames or even a historical comparison of like thinkers is definitely possible. Nonetheless, the period divisions used in this book are not far removed from local historical periodization, even if these too have been influenced by Western scholarship and thought over the years, particularly Marxism, its predecessors and challengers. To be clear, I am not suggesting that there is a common human trajectory, even in the modern era. However, the purpose of the book is to provide an overall chronological narrative and viewing similar thinkers at similar times makes the most sense. The real test of the periodization is the coherence and value of the comparisons for helping us understand political thought. For that reason, loose periodization is not a problem so long as the comparison is informative and productive.

\section{WHAT IS IT THAT IS COMPARABLE?}

One "soft" version of comparative conceptualization might be the notion of equivalences, such as that used by Anthony Parel drawing on the 
work of Eric Voegelin. ${ }^{1}$ Parel provides three sets of equivalences as: "the Aristotelian politikos, and the Confucian junzi, Indian dharma and premodern western notions of 'natural rights', the Islamic prophet-legislator and Platonic philosopher-king." One can easily question how similar each of these sets are but more important for our purposes is that this use of the concept of equivalences appears to misread Voegelin. Voegelin argued that the search for the meaning of concepts is itself dependent on the concepts it uses to decipher concepts. The process is a self-reflective one - a theory of equivalences - in which one must be conscious of the historical and cultural position of one's own enquiry. Voegelin found in the end that there were no constants in history because history is a process of discovery that itself is relative to what was found before. ${ }^{2}$ On this reading, the quest for equivalences is ambiguous. Parel appears to be using the concept as similar or similar enough or, more worryingly, as the specific historical or cultural manifestation of the same universal idea. This is another area where the focus on differences is important. There has to be enough similarity to make it interesting but it is the differences that will be most important. One must ask: what is left after the comparison? It does not mean that two thinkers or concepts are the same once they are stripped of all historical or cultural baggage. There can be two distinct formulations with profound differences but it does not stop one from suggesting that there is a core around which both can be compared.

This is not a relativist position. In fact, the worst types of comparisons are those that try to demonstrate how different two ideas (or societies or civilizations) are. There are going to be some basic commonalities to all political realms no matter when and no matter where. It makes no sense to focus on trivial differences or differences in style and the mode by which ideas are expressed or used. The idea of a core conception implies the potential for a universal form but also the impossibility of finding it because such a form can never be defined precisely, and how the form is manifested will vary endlessly. There are, without a doubt, ideas and dilemmas with continuing significance, thus the notion of perennial issues and ideas in political thought, but it is a mistake to believe that there can be a fixed unchanging meaning and manifestation of an idea universal to all politics. At the same time, the existence of comparable ideas or sets of ideas to compare, contrast, borrow, adapt and build upon is not absurd.

1 Anthony Parel (1992) "The Comparative Study of Political Philosophy," in Anthony J. Parel and Ronald C. Keith, eds, Comparative Political Philosophy: Studies Under the Upas Tree, Lanham, MD: Lexington Books: 12.

2 Eric Voegelin (1990) "Equivalences of Experience and Symbolization in History," in Ellis Sandoz, ed., The Collected Works of Eric Voegelin, Vol. 12: Published Essays, 1966-1985, Baton Rouge, LA: Louisiana State University Press: 115-133. 
A linguistic analogy of soft conceptualization is how the same word can denote similar but different meanings. For example, one can use the concepts of pinpoint, pinned down, pinwheel, and so on which are all centered on the notion of a "pin" or small sharp object with the ability to hold something in place or denotes a degree of precision or fixation, depending again on the context. This analogy is apt because the history of political thought often turns on concepts such as the use of "ren" (仁) as humaneness or " $l i$ " (禮) as ritual in Chinese political thought or "dharmal dhamma" in Indian thought or "the city" in Western and Islamic political thought, which shift meaning over time and depending on context. A good example is the notion of "liberty," which has been important historically in the West but not always in the same way, ${ }^{3}$ and has evolved as it has become a global concept despite being articulated and developed in significantly different ways. ${ }^{4}$

Even if one finds a concept that seems specific to a context, it is important to look for it in the other civilization with which comparison is being made. It is not a matter of unreasonably forcing similar concepts in another society into the role played in the comparator. It is simply that the role of the concept in both the comparator and the original context are put into relief when the comparison is made. Identifying differences in the conceptualization and use can only benefit the analysis. One example is concept of ritual in East Asian thought. Ritual exists everywhere, it can be conceded, but does not have the same role theoretically or practically elsewhere. As anthropologists are apt to show, ritual has surprisingly more relevance than one might think at first even in modern societies. Important ideas have some commonality across civilization and even if one could find one that did not, then that can be interesting too.

\section{LANGUAGE}

This leads us to the role of language and its analysis, which is often regarded as central to the study of political thought ${ }^{5}$ largely as a legacy of the Cambridge

\footnotetext{
3 Quentin Skinner (1998) Liberty before Liberalism, Cambridge: Cambridge University Press.

${ }_{4}$ See, for example, Alain Roussillon (2001) “'Ce qu'ils nomment 'Liberté...' Rifā'a al-Ṭahțāwī, ou l'invention (avortée) d'une modernité politique ottoman," Arabica, 48(2): 143-185; and Douglas Howland (2001) "Translating Liberty in 18th Century Japan," Journal of the History of Ideas, 62(1): 161-181.

5 J.G.A. Pocock (1971) Politics, Language and Time: Essays on Political Thought and History, Chicago, IL: University of Chicago Press; and Quentin Skinner (1969) "Meaning and Understanding in the History of Ideas," History and Theory, 8(1): 3-53.
} 
School and the influence of Wittgenstein on philosophy in particular. It is inevitable that understanding a text requires understanding of the linguistic context in which the original text was produced, though this does not exhaust the issues related to language. Even attacks on linguistic contextualism largely accept the validity of the practice even if the argument is that emphasis should be placed as well on other sources of possible meaning. ${ }^{6}$

In comparative political thought the key problem is that of translation. Few can master two or more languages to a degree that allows them to compare across civilizations effortlessly. Even then the logic of comparison based on subtle judgments of meaning has to be explained and justified. In the case of a project involving multiple ancient languages or the entire scope of the world history of political thought, reliance on translation is inevitable. This problem can be addressed to a large degree by "triangulation." Triangulation in this context is the method by which the reading of two or more translations of the same work enables one to check the robustness of meaning. Special care is needed when analysis hinges on a key word or phrase. Many key terms have complex meaning which cannot be captured in a simple direct translation so one must ensure the discussion of key concepts and terms is treated with nuance and reflects the ambiguity and multiplicity of possible meanings. In this book, I have attempted to go back to the original source in the original language where possible, though, for the convenience of readers, English language translations are usually cited (or the nearest Western language equivalent).

The main problem with lack of knowledge of the original language of a text is not an inability to translate accurately. It is more that the hermeneutic possibilities inherent in the text are often better understood in the original or at least by someone with wider experience of the language and the possibilities of the language, particularly as language was used in the society of the time in which the text was written. In any case, it helps to have some understanding of the nature of the language being used. For example, classical Chinese possesses both "lexical ambiguity" and "optional precision" which makes it difficult to interpret precisely in every case. "Lexical ambiguity" occurs for a variety of reasons but includes the situation in which some Chinese characters can be forced to be read as others because they are a homonym of a word but have a different original meaning in order to avoid repeating the same word over again. However, this leads to vagueness and works against semantic precision. ${ }^{7}$ It is "optional precision" because Classical

\footnotetext{
6 Mark Bevir (1992) "The Errors of Linguistic Contextualism," History and Theory, 31(3): 278.

7 Archie Barnes, Don Starr, and Graham Ormerod (2009) Du's Handbook of Classical Chinese Grammar, London: Alcuin Press: iii.
} 
Chinese often does not provide the key information on case, number, gender and other grammatical fixtures that can constrain the meaning of sentences in other languages. ${ }^{8}$ It may not be so much that this economy of style caused few problems to contemporary readers ${ }^{9}$ as much as it enabled the text to set fire to the imagination, increased its appeal and was only constrained by subsequent interpretation by schools of thought or "tradition."

Some works of political thought are ambiguous and that may be why they are considered great. The great works of literature tend to be open to a reading that speaks to the widest possible audience or at least a broad audience of the educated. ${ }^{10}$ It might be too much to argue that such works are intentionally vague but certainly many works of political thought are open to interpretation and this is why they appeal to different groups. As Stanley Rosen has put it "no text worth reading wears its meaning on its sleeve." 11

A final problem with the use of language is that some thinkers may intentionally not say what they mean. Some engage in irony so that they may mean something different and even opposite to what they appear to be saying. In a conversation we can pick up clues when a person is being sarcastic or ironic but in texts in another language or in a completely different historical context, it may not be clear. Another possibility is a hidden core meaning behind the idea or ideas. For example, the text might hide an esoteric meaning which is only obvious to those who understand its deeper structure and implications. Leo Strauss is associated with this type of approach ${ }^{12}$ but there are also more recent proponents. ${ }^{13}$ Strauss has been critiqued, most notably by Drury ${ }^{14}$ as hiding his own esoteric political agenda in his revelation of esoteric meaning in ancient political thinkers. Others are not so sure that there is a clear agenda in Strauss. ${ }^{15}$ Therefore even in this case of a scholar who explicitly recognized esoteric meaning and its interpretation, there is no consensus on what was meant and this shows the difficulties of determining if and when one should look for hidden agendas.

\footnotetext{
8 Barnes et al. (2009) Du's Handbook of Classical Chinese Grammar: xv.

9 Barnes et al. (2009) Du's Handbook of Classical Chinese Grammar: vi-v.

10 Jonathan Bates (2008) The Genius of Shakespeare, London: Picador.

11 Stanley Rosen (2003) Hermeneutics as Politics, 2nd edn. New Haven: Yale University Press: 142.

12 Leo Strauss (1952) Persecution and the Art of Writing, New York: The Free Press.

13 Arthur M. Melzer (2014) Philosophy Between the Lines: The Lost History of Esoteric Writing, Chicago, IL: University of Chicago Press.

14 Shadia B. Drury (1985) "The Esoteric Philosophy of Leo Strauss," Political Theory, 13(3): 315-37.

15 Michael Frazer (2006) "Esotericism Ancient and Modern Strauss versus Straussianism on Political-Philosophical Writing," Political Theory, 34(1): 33-61.
} 
Even so, there are understandable reasons why a thinker might not set forth his or her views in a forthright manner. It might be that the thinker is trying to explain ideas to an audience which needs to be addressed in a specific way. The true intention of the author is masked by the need to communicate more effectively or cautiously. Ideas that are controversial might be masked through an argument that appears non-threatening to existing sensitivities but conceals a deeper position which challenges conventional assumptions. The notion usually takes the form that the thinker is rational but must hide their true views by reference to traditional myths and forms of piety. There is a general consensus that the medieval Muslim philosopher al-Farabi, for example, may have written his works with this concern in mind though it is also possible that he wanted to compel his readers to think for themselves and reach their own conclusions, which is another reason why an author might leave a text open to interpretation. ${ }^{16}$

Good translations and multiple translations with many footnotes to tease out the nuances of meaning of words and phrases can enable the reader to make a judgment about the possible meanings of a text but it is not a complete substitute for having a direct grasp of the text in the original language. Key passages can be ambiguous or have complex implications. Often translation involves simplification or adding material that at best is implicit but is added to make sense of a passage in a different language. If we rely on the translator to make decisions about what a text means in these cases, then we miss an opportunity to think for ourselves. It is such ideas and sections of text that must be the focus of our hermeneutic resources in translation or not.

\section{METAPHYSICS}

For a history of political thought, it is essential to raise those aspects of thought that are relevant to politics, broadly conceived. Politics in the narrowest sense of the term is the nature of rulers and the ruled. That is, who controls power to make major decisions with an impact on society and how those in a society relate to those with power. In doing so, it is often necessary to look at the underlying metaphysics, logic of ideas and ethics in order to enhance understanding of the political ideas of the various thinkers. Often metaphysics or logic explains or has implications for ethical or moral values which are expressed in human relationships at the basis

16 Charles E. Butterworth and Thomas L. Pangle, "Foreword," in Al-Farabi; Muhsin Mahdi trans. (2001) Alfarabi: The Philosophy of Plato and Aristotle, revised edn. Ithaca, NY: Cornell University Press: ix-xii. 
of politics. This includes the logic and ethics of being a ruler, subject or citizen. The sequence of links is as follows:

metaphysics and its logic $\rightarrow$ ethics/morals $\rightarrow$ human relations $\rightarrow$ politics

Highlighting the role of metaphysics might be contentious but comparative political thought cannot avoid discussing it. Metaphysics is simply that which cannot be explained by conventional empirical science. It is implicit in ethical and political ideas so we can best compare when we make it explicit. In doing so, one will notice differences in how societies approach the world. For example, one could make the crude generalization that Western thought is based on the notion of monism and being, whereas Eastern thought is traditionally focused on plurality and emptiness or nothingness. That is, Western thought seems to try to create logical systems that result in a single truth or being that resolves all contradiction but Eastern thought is often more dialectical, violating the notion of the "excluded middle" central to Western logic, to explore unresolvable but productive contradictions and paradoxes. This difference has been used to dismiss non-Western approaches as mysticism, which is seen as bad, but in fact there is simply a difference in approach. The real problem is that metaphysics is often hidden in modern Western thought in order to bolster its scientific credentials and to provide a contrast to the more "traditional" and "exotic" non-Western forms of thought with more explicit metaphysical underpinnings. This book will attempt to highlight metaphysics, including that in the West and in modern times, and point out the value of understanding the role of metaphysics in political thought regardless of its origins.

There are three basic metaphysical threads running through this book. One is neo-Platonism, which emerges in Antiquity, runs through the late middle ages and still has an influence today, not just in Christian and Islamic thought but also in secularized thinking in the societies in which these religions have been historically important. The second is Taoism, or more precisely, the development of Taoist philosophy by the Literati who are commonly referred to as Confucians. These ideas have been influential in East Asia and continue to linger today. The third is Indian metaphysics that starts with the Upanisads but also includes Buddhism as well as what is called Hindu thought. This has an influence not just in South Asia, including Southeast Asia, but also through Buddhism in East Asia (where it was sometimes combined with Taoism), and may have possibly influenced neo-Platonism as well. These traditions are important and necessary to any understanding of the history of world political thought.

The problem is that metaphysics is often mixed up with the concept of 
religion, which is very difficult to define in a historical sense, as we will see. I argue in this book that the modern separation of religion and political philosophy is a barrier to understanding the history of political thought, not just in the non-West but in the West as well. It is easy to point to "religion" in a modern sense when it appears in the past and in other societies, but views on what is religion are bound up with modern Western thought, explicitly and implicitly. By focusing on metaphysics I try to finesse the issue to some degree, but I often have to insist that the role of what appears to modern sensibilities to be religion in political thought is legitimate and perhaps inescapable. It is also very much related to ethics. It is possible to be ethical without being religious but the source of non-religious ethics is just as grounded in metaphysics as religious ethics, god, gods or no god.

\section{IMPORTANCE OF DIFFERENCES WITHIN SIMILARITIES}

I have tried to explore the clearest or most obvious or most noted similarities and differences between thinkers or schools of thought first. At the same time, I have tried not to allow myself to be satisfied with superficial similarities. Often the differences even in the most similar thinkers are most revealing of the nature of their thought. Initially one should make as strong a case for similarities as one can but then one must acknowledge the points on which they are different and consider why that is the case. This is the principle of differences within similarities which is crucial to good comparison. One should challenge similarities by pointing out the remaining differences until there are no unchallenged similarities left. Challenging apparent similarities is methodologically more significant because "negative evaluation is intrinsically more instructive than positive valuation because the justification of a negative evaluation automatically involves a contrast that the justification of the positive does not. . ."17 It provides additional evidence of the relationship between two arguments that brings them into sharper focus. Similarity is often too flexible to ground the formation of meaningful categories and it is only a common theory or context that can provide the basis for categorization, not similarity alone. ${ }^{18}$ Humans tend to see similarity even when it is weak or even non-existent because we use superficial similarity or analogical reasoning

17 Maurice A. Finocchiaro (1981) "Fallacies and the Evaluation of Reasoning," American Philosophical Quarterly, 18(1): 17.

18 Robert L. Goldstone (1994) "The Role of Similarity in Categorization," Cognition, 52(2): 125-157. 
when processing information. ${ }^{19}$ Given appropriate guidance, however, it is possible to identify structural similarity by focusing on underlying relations between elements of the things being compared. ${ }^{20}$ This suggests that we must look deeper to understand the extent of any similarity and the nature of the differences is crucial to doing that.

The comparative politics literature contains hints for how similarities might be conceptualized in comparative political thought. ${ }^{21}$ Anyone who examines political thought comparatively can sympathize with Sartori's critique of conceptual stretching, which, he notes, is also "conceptual straining." 22 The symptoms of this problem include vague and amorphous conceptualizations, that is, concepts without clear definitions and the attempt to make concepts value free, or more accurately, "universal." $\mathrm{He}$ particularly notes that studies of non-Western political systems have forced comparative politics specialists to use concepts drawn from the West to analyze politics outside the West which he implies may not be valid. He was concerned that by stretching concepts scholars were taking the easy path but one in which "gains in extensional coverage tend to be matched by losses in connotative precision." 23 One advantage that comparative thought has over comparative politics is the systems of thought have an internal logic which can be used to tease out meanings and provide a contrast to similar concepts in other civilizations. There is no assumption of a universal rule-bound social science that drives political processes in political thought as there has tended to be in comparative politics, at least at the time Sartori was writing.

Even so there may be some value in considering comparative politics research strategies such as those proposed by Collier and Mahon, ${ }^{24}$ including the notion of family resemblance, radial categories, and even the Weberian "ideal type." One must proceed cautiously, however. Family resemblance makes sense only if there is a set of shared characteristics but in the case of civilizations not in contact with one another then the

19 Brian H. Ross (1989) "Distinguishing Types of Superficial Similarities," Journal of Experimental Psychology: Learning, Memory, and Cognition, 15(3): 456-468.

20 I. Blanchette and K. Dunbar (2000) "How Analogies are Generated: The Roles of Structural versus Superficial Similarity," Memory and Cognition, 28(1): 108-124.

21 Sara Jordan and Cary J. Nederman (2004) "Between Sartori and Skinner: Methodological Problems in the Study of Comparative Political Thought," Annual Meeting of the American Political Science Association (APSA), Chicago, IL.

22 Giovanni Sartori (1970) "Concept Misformation in Comparative Politics," American Political Science Review, 64(4): 1034.

23 Sartori (1970) "Concept Misformation in Comparative Politics": 1034.

24 David Collier and James E. Mahon, Jr. (1993) "Conceptual Stretching Revisited: Adapting Categories in Comparative Analysis," The American Political Science Review, 87(4): 845-855. 
assumption might be misleading. Shared characteristics might be more useful in the case of diffusion and adaptation of ideas in different contexts. Radial categories assume a certain universal core upon which the category can be developed and a pure universalistic approach may not be appropriate if it assumes fixed starting points. Weberian ideal types also hold similar problems especially when the types are drawn from a theory that effectively denigrates certain types of thought, for example, viewing religion or rationality on an evolutionary scale, which will make some systems of thought seem less developed and therefore less worthy of consideration than others. Nonetheless, it makes sense to articulate and apply clearly defined concepts and extend them appropriately in order to distinguish between the meanings of a concept in any given situation.

One solution to the problem of assessing the nature and extent of similarity can be to develop a rationale for why two thinkers appear to be similar (a theory) and provide evidence that there is a similarity for the reasons posited. However, one must take care because premature theorization can also be a block to enhanced understanding. ${ }^{25}$ At the same time, if we are going to meaningfully compare or tease out similarities then there has to be a rationale for doing so. The more robust the rationale, the more theoretically sophisticated the comparison is likely to be.

This task is aided when thinkers are compared on each topic or concept one by one rather than looking at each thinker as a whole separately. It is better to compare in fine grain point by point to tease out the similarities as well as the crucial differences. Doing a comparison of thinkers or schools of thought as a totality in discretely separate analysis tends to lack nuance and detailed engagement with the ideas being compared. It is too easy to finesse the argument when it is in broad brush strokes in two distinct blocks of discussion. In contrast, differences more clearly emerge at the level of finer conceptual and logical granularity when comparing specific ideas or approaches. For example, two thinkers may advocate "nature" as a guide to political praxis but it depends on how nature is defined and can or should be made relevant to politics. Only by comparing thinkers on the micro-level will we have deeper understanding of what each thinker meant. Every effort should be made to highlight the similarities to other thinkers and the differences within those apparent similarities at the finest grain level of analysis possible.

In this book, however, it has only been possible to provide this interwo-

25 Albert O. Hirschman (1970) "The Search for Paradigms as a Hindrance to Understanding," World Politics, 22(3): 329-343, and though Hirschman may be misusing the concept of a paradigm, his point regarding the dangers of premature theorization, particularly in a cross-cultural context, is in general still correct. 
ven, fine grain analysis in only a few places. There are practical reasons for not doing so consistently in an overview of this type. Most importantly, it would be a much longer book if the comparisons were carried out in more detail than present throughout the entire work. In addition, my aim is to be more suggestive of the potential for comparison for others than to do all the comparison work in detail. This is partly because this book is meant to help others see the scope of possible comparison and broader brush strokes are better for this task. There is also the danger that any comparisons made in detail will suggest that the comparison between two thinkers is exhaustive when in reality it is possible to compare thinkers in many different ways, even on the points raised here. I hope that the few places in which two thinkers' concepts are contrasted on finer points of difference provide some insight into how such comparison can be best conducted.

\section{HISTORICISM AND UNIVERSALISM}

This project is explicitly historicist but it is crucial to define what that means in any given situation. The simplest aspect of historical impact is context, that is, the range of historical possibilities and the nature of events and ideas that existed at the time. Obviously historical context does matter but one must explain why. All historical conditions are unique but that does not mean that they cannot be compared. One needs to make a case for or against comparability. It is not a given or impossible in any case.

One must make an effort to avoid anachronism. One must ask what did it mean then? It may require a conscious steer away from what it can mean now. At the same time current usage and meaning (significance) can be useful as a contrast and for making the ideas accessible. Certainly the relevance or possible relevance of any ideas for contemporary readers can have a great heuristic value, which will enhance understanding and engagement with the ideas.

One must take care to avoid universalism, that is, the view that there is only one meaning and purpose to similar ideas everywhere based on a shared universal basis to politics. Yet, we should also reject relativism: the view that thinkers and ideas cannot be compared at all because every context is different. The only case I can make for this middle way between universalism and relativism is the notion of an irresolvable dialectic where the tension between two opposing ideas are left in free play, that is, without resolution in conclusion or synthesis. It is better to allow two similar but still distinctly different concepts to stand in constructive opposition to one another rather than try to dissolve the differences by positing a universalistic core incorporating both. As noted above, dialectic methodology is 
underrated in Western thought if perhaps overrated in Eastern thought. It is useful, however, in circumstances where there is no easy single answer and the tension between two principles produces interesting results.

Universalistic categories such as pre-modern, early modern and modern imply progression and development in a way that is unhelpful. This is true when modernity is seen as a special case. For this reason, supposed alternatives such as "multiple modernities," 26 "axial age," 27 and "new axial age" 28 are more of a hindrance than an aid to the process of reading political thought comparatively. ${ }^{29}$ In particular the notion of modernity tends to trivialize non-Western, classical or "medieval" ideas, because they are deemed traditional (so not modern) by definition. One must consciously confront the ideological and temporal limitations of such periodization. Even when the notion of ancient or medieval thought is used in this book, it is introduced explicitly and critically. As noted above, the terms ancient or medieval are used in their loosest senses because the term will not cover an exact replica of the periodization from one civilization to another.

There is a sense in which a degree of universality is necessary to comparative political thought. If there is no basis for understanding across civilizations, then the whole enterprise is pointless. Yet, there is an argument that it is not possible for someone from one tradition to comprehend another that is substantially different, an approach often associated with Richard Rorty. This is a radically historicist approach, based on the idea that philosophy itself is highly contingent and based on circumstances peculiar to the West. ${ }^{30}$ Rorty seems to insist that any comparison is so deeply situated in its own culturally bound conceptual scheme that any attempt at comparison can be neither useful nor neutral. He seems particularly dismissive of the content of non-Western thought when he rejects Davidson's approach to understanding language that all humans hold true beliefs about those same things ${ }^{31}$ by saying that Davidson's argument holds only for whole natural languages, not for "specialized jargons," 32 which

26 Shmuel N. Eisenstadt (2000) “Multiple Modernities," Daedalus, 129(1): 1-29.

27 Karl Jaspers (1953) The Origin and Goal of History, New Haven, NJ: Yale University Press, and Robert Bellah and Hans Joas (2012) The Axial Age and Its Consequences, Cambridge, MA: Harvard University Press.

28 Yves Lambert (1999) "Religion in Modernity as a New Axial Age: Secularization or New Religious Forms?" Sociology of Religion, 60(3): 303-333.

29 Anthony Black (2008) "The 'Axial Age': What was it and what does it signify," The Review of Politics, 70(1): 23-39.

30 Richard Rorty (1989) "Review of Larson and Deutsch (1988) Interpreting Across Boundaries New Essays in Comparative Philosophy," Philosophy East and West, 39(3): 334.

31 Donald Davidson (2001) "On the Very Idea of a Conceptual Scheme," in Inquiries into Truth and Interpretation, Oxford: Oxford University Press: 183-198.

32 Richard Rorty (1989) "Review of Larson and Deutsch": 336. 
presumably prohibits access to the meaningful content of non-Western thought. James Tartaglia points out that this is not consistent with Rorty's overall orientation, which is more open-minded as accepting of dialogue and suggests that he was forced to take this position because the possibility of comparative political thought undermines his argument that philosophy is culturally specific and thus Rorty's pragmatism. ${ }^{33}$

Rorty's argument, however, does imply that the attempt of comparison, especially by Western thinkers in their current position of dominance, can do damage if one insists that another society compare its practices and ideas to that of another. It is true that one needs to look at who benefits (theoretically and empirically) from the approach to the interpretation taken and whether or not conceptual schema or even specific ideas can be used at the expense of others. The argument is that a single universal morality is detrimental to some. It is true that moral imperatives have their opposites: happiness is often seen to be a goal of good politics but one can argue that suffering is sometimes necessary and even helpful; altruism and selflessness are often praised but self-interest often seems a more efficient and effective motivator; equality is held by most moderns to be preferable but inequality is empirical fact and needs to be taken into account; Nietzsche has argued that pity and compassion can be used to keep others in a position of weakness; and modern Western respect for individuals can come into conflict with the needs and goals of the larger community. One might even argue that all standards of morality and political practice are against nature and distort humans (this is the Taoist argument as we will see). However, this would be true within civilizations as well as between them. All one can do is try to make sense of as many different approaches to politics and related ethical arguments to examine the range of possibilities and make one's own choices. Consideration of the broad spectrum of world political thought is the best way to do this.

\section{THE PRINCIPLE OF CHARITY AND REFLEXIVITY}

Perhaps the most important methodological consideration in comparative political thought is the principle of charity. For the most part the effort here is to attempt to reconstruct the possible meaning of the texts of each thinker. Once we have accepted that reconstruction is valid or at least plausible, we must then consider the motivations for reconstruction. This could focus on a scholarly search for truth but we must heed Gadamer's warning

33 James Tartaglia (2014) "Rorty's Thesis of the Cultural Specificity of Philosophy," Philosophy East and West, 64(4): 1017-1038. 
that we can never entirely succeed in reconstructing historical texts: "They remain fruit torn from the tree. Putting them back in their historical context does not give us a living relationship with them." 34 Instead, he urges us to be aware of what we want the text to do for us: ". . . the essential nature of the historical spirit consists not in restoration of the past but in thoughtful mediation with contemporary life." 35 In theory the principle of charity can be both integration (that is, how do I make sense of this thinker for myself or my audience) and reconstruction (that is, what is possible that this originally meant). This means we can define integrative charity as trying to making sense of the ideas of others for one's own purposes but also making the best case for these ideas in doing so. We can similarly define reconstructive charity as making sense of ideas using the available evidence of the intentions of the author and the influences of the times in which a text was written to formulate an interpretation. It cannot entirely escape integrative charity. For example, a logical/rational reconstruction might contradict a spiritual reconstruction. That is, if you believe that the thinker is a rational thinker and dismiss miracles as myth then one reconstruction is possible but if you think that miracles are possible, then another completely different reconstruction is possible. It depends what one is seeking to get out of the text.

It is in this situation that reflexivity is crucial. We must try to be conscious of the "baggage" or prejudgments we bring to the reading of a text. This includes one's own temporal situation (historical), cultural background (American, British, Christian, atheist, and so on) and theoretical approaches taken (virtue ethics, Marxian, Hegelian, and so on).$^{36}$ Modern readers can often misunderstand because they read texts anachronistically based on modern norms and beliefs. By acknowledging potential prejudices, we can understand possible obstacles to understanding a text.

Religion is a real problem in this study of this kind, particularly when religion is viewed anachronistically. Moderns and academics tend to be skeptical of religion. The separation of religion and secular life is a deeply ingrained notion in the West, especially in academic circles, and to a degree in all modern societies (including modern enclaves in what are called "traditional" societies). It is not just the problem of whether political thought and so-called religion should or can be separated because it is questionable in many historical periods and societies whether the two should or can for

\footnotetext{
34 Hans-Georg Gadamer (1989) Truth and Method, 2nd edn. London: Sheed and Ward: 168.

35 Gadamer (1989), Truth and Method, 2nd edn: 169.

36 P. Bourdieu and L.J.D. Wacquant, eds (1992) An Invitation to Reflexive Sociology, Cambridge: Polity Press.
} 
the purposes of analysis. Yet, modern approaches to the role of religion are based on the assumption that religion, on the one hand, and secular matters, such as political power, on the other, should be separate. In this context, non-rational and un-scientific ideas are difficult to take seriously. However, everyone has non-rational and un-scientific ideas - even the most modern of us. Again this is an area where an applied understanding of metaphysics is essential. An effort is required to understand why someone, including very intelligent individuals, would believe in ideas with which one might not agree. One should certainly not deal with the problem by means of pathology, that is, analysis based on search for causes that assumes deficiencies such as ignorance or delusion that might explain why others hold what might appear to be non-rational and un-scientific beliefs. A strong and valid case must be made for any form of thought in order to understand it. One has to believe in an argument to a degree, even just temporarily, in order to critique from inside and outside.

A similar problem occurs with the inclusion of what is usually considered "ideology" as though some approaches to political thought such as Marxism or anarchism are somehow distinctly of less worth than "standard" thinkers and texts such as Thomas Hobbes and the Leviathan or John Stuart Mill and On Liberty. The distinction between "political philosophy," which is based more on modern academic philosophical analysis, and "political thought" is ignored here as well because modern academic philosophical analysis can and must be historicized and seen as a form of political thought as well in order to be understood comparatively.

This means that another aspect of the principle of charity is to accept that there is going to be a diverse genre of works with which one must engage. Often non-Western political thought is not considered political thought at all. Buddhist sutras are a case in point. However, if you look at the range of genre, non-Western political texts are roughly similar to Western ones: advice for rulers, history, literature, theology, ethics, pamphlets, cosmology, ontology, epistemology, epics, and so on. In the West as well there are many cases where non-academic thought is considered to be part of the canon of political thought so do not dismiss the other of other civilizations because it does not seem like political thought as you know it (such as being too religious, for example, or a work of fiction, as in Homer's Iliad, More's Utopia or Rousseau's Emile, and so on). Many thinkers need to be taken more seriously, especially those who do not seem obviously "political" but are given the context in which they were read (here I am thinking of early Taoism, the works of Zhu Xi, and so on).

In the end, the principle of charity simply means that one must give each thinker the benefit of the doubt. Make the best case you can for their ideas, 
explaining or resolving any problems or contradictions rather than criticizing them for it. However, do not be fooled into thinking that charity does not permit critical analysis. In fact, it is only by comparing the charitable interpretation with existing and potential critical interpretations that the thought will be most thoroughly understood.

Any critique of the ideas of past thinkers must be based on both the evidence and reflexive sensitivity. For example, one must be particularly wary of rejecting the views of thinkers because certain views are unacceptable now but could be seen as valid in another place and another time. Even within the Western tradition, Plato and Aristotle are usually not entirely rejected because they accepted the legitimacy of slavery, nor can one completely dismiss Locke because he preached tolerance but excluded atheists. It does not mean we need to completely forgive thinkers of the past for ideas that are offensive today but it is also true that thinkers need not be held to contemporary standards to the extent we dismiss what is of potential value. In most of these cases, it is more important to consider whether the system of thought being proposed inherently leads to problematic outcomes or can be salvaged based on the overall positive contribution that potentially flows from the ideas put forward even if some ideas need to be omitted or reinterpreted.

The book also seeks to give life back to many of the ideas discussed by authors in different times and traditions. In contemporary political thought there is a tendency to create and analyze abstract concepts as ethics, democracy, authority, and so on as generic entities shorn of their original context or historical development. Even when they are discussed in historical context they are treated as quaint antique artifacts with little relevance for those living today. By bringing these thinkers and ideas back to life, and saving them from neutralization as mere conceptual background, there is hope that they can be made relevant to the world today. A "Confucian" view of the world can contribute much to understanding the role of ritual for example in modern politics. Buddhist political ethics can and has made a major contribution to environmental political thought. Differences in how law, power, deception, loyalty, belonging, and other concepts that arise again and again in the history of political thought have continuing importance today.

\section{VALIDITY ISSUES}

Validity as a methodological issue is normally defined as trying to ensure that a concept or measurement of a concept corresponds sufficiently to the phenomena that one is studying. Validity is determined by the strength 
or ability of the concept to cover the cases it argues can be covered by the concept.

Case selection is the first and perhaps most important aspect of validity in textual analysis. Case selection is relevant when we argue that a thinker holds a particular set of views, fits with a specific school of thought, is potentially the key figure or exemplar of a school, and most crucially when a text or passage in a text is seen as meaningful or representative of a specific view or set of views. In some cases, the categorization of the thinker into one school or another needs to be problematized and the nature of concepts being used must be distinguished from the modern English language meaning of the term. In these cases, the use of the original language is a necessity and not pretentious.

One might also make a distinction between what I call internal and external validity, though I apply it in a different way than used in other fields of inquiry. Internal validity is centered on the text. What does the thinker actually say? There is often a gap between what the secondary literature says a thinker says and what is actually written in the texts. It would be too tedious to add long quotations from original text but they are the basis for any statements and are clearly cited in this history so the reader can check the text against my reading. There is also the larger issue of viewing specific passages and ideas in the larger context of the entire work or body of work of the thinker. This requires a close and accurate reading, not just of particular passages but of the parts of the text in relation to the whole work or the entire oeuvre of the author. This often requires one to identify textual issues. One must assess accurately if the passage or text conveys the ideas of the person being studied. Often there are later accretions of interpretation that require a text to be "unpacked" and reordered.

External validity focuses on how the text and one's interpretation of the text relate to the world, both of the author and history in general. How is it relevant? Is it relevant in the ways that the author and his interpreters, then and now, appear to have intended? In the first instance it revives a role for conventional hermeneutics based on the evidence of historical circumstances. It also means that information relating to the author is important to provide context. However, this should not be entirely the focus of the study. It is discussed only if it enhances substantially understanding of the nature of the arguments made. The idea that the intention of the author is the sole arbiter of the correct meaning of the text is wrong and impossible to determine in most cases anyway. It is true that evidence drawn from the writings and history of the author and contemporaries (friendly and hostile) can enhance our understanding of the text. At the same time, it is crucial to understand what it can mean in other political contexts, including to readers today. What is the enduring appeal of the ideas that mean 
that they have been preserved, transmitted and seen as valuable over time, including today?

\section{THE KEY QUESTIONS AND TOPICS}

The key questions I always had in my mind when writing were: What was written of importance by these thinkers and why is it important? What are the similarities and differences between the thinkers and others who seem similar? Are they really similar and how are they different even if some similarity can be plausibly attributed? What is the basis of the similarities and differences? Finally, what contribution do they make to our understanding of political thought in general?

The general pattern of the chapters is to look at the historical context briefly, then to consider the main approaches in the period and the tendencies underlying each one. There is always a focus on metaphysics and cosmology, which is crucial, as argued above, and this is often part of a larger discussion of the role of ethical and religious systems in political thought. The chapters tend to conclude with a consideration of views of thinkers and systems of thought regarding what can be called issues of equality but are essentially how the average person and particularly women as a whole are treated. The treatment of the "masses" and women reveals much about the underlying metaphysics and ethics of a system of political thought.

The decline of teaching of the history of political thought in the past few decades is in part due to the criticism that it only focuses on "dead, old, white men." A world historic view deals with the problem of only focusing on "white" thinkers (whatever that is supposed to mean). The thinkers in this book are still mainly dead (though not all) but that is inevitable with most history. However, it became clear that a focus on the role of women in the history of political thought was essential. First of all, the role and status of women as viewed by major political thinkers reveals much about different systems of thought. There was also the problem of the fact that most thinkers were addressing a male audience. While there is no attempt in this book to anachronistically make the thinkers gender neutral, where ideas are potentially applicable to all humans, then it is fair to point this out. At the same time, views on women, both positive and negative, are clearly set out. This focus on women is not an exercise in tokenism because, as the reader will see, women play a key role in the history of political thought, not just as crucial subject matter for male thinkers but also as important contributors in their own right, which is even more obvious if one looks globally. 
Overall the range of thinkers and topics covered should present the reader with a good understanding of the basic outlines of the world history of political thought. It is not perfect but it should be a good start. 
J. Babb - 9781786435538 